\title{
Do Silencioso ao Sonoro 3D - breve reflexão sobre público e indústria cinematográfica
}

\author{
Rosana Stefanoni \\ Mestranda do Programa de Pós- \\ Graduação em Meios e Processos \\ Audiovisuais da ECA-USP, sob a \\ orientação do Prof. Dr. Eduardo Vicente, \\ formou-se pelo Curso Superior de \\ Audiovisual da ECA-USP em 2010, tendo \\ se especializado em roteiro, montagem \\ e som. Entrou na carreira sonora em \\ 2008, no estúdio Casablanca Sound. Sob \\ a supervisão de som de Luiz Adelmo, \\ fez o foley de diversas produções \\ do cinema e da TV como: "Corpos \\ Celestes" (Marco Jorge, 2011); "Meu \\ País" (André Ristum, 2011); “O Palhaço" \\ (Selton Mello, 2011); e as séries \\ "9mm: São Paulo" (Michael Ruman, \\ 2009/2011) e "Sessão de Terapia" \\ (Selton Mello, 2012). Atualmente, junto \\ com Alan Zilli, forma o Departamento \\ de Som da produtora $\mathrm{O} 2$.
}

\begin{abstract}
Resumo: Com o recente lançamento mundial das novas salas de exibição com som tridimensional, podemos estar próximos de uma transformação da linguagem do cinema. A dinâmica entre a demanda do expectador e o tripé produção/distribuição/exibição existe desde os primeiros tempos do cinema, sendo responsável pela criação do modelo de exibição e da própria linguagem cinematográfica que conhecemos hoje. Esse artigo procura mostrar como a dinâmica entre exibição, púbico e produção, principalmente no que se refere ao som, impulsionou o desenvolvimento do cinema até que se consolidasse o filme sonoro.
\end{abstract}

Palavras chave: Cinema Sonoro - 3D - Exibição - linguagem cinematográfica

Abstract: With the release of tridimensional sound movie theatres around the world, we can be close to a film language transformation. The dynamic between public demand and the triade production/distribution/exhbition exists since the early cinema, it is responsible for the establishment of today's exhibition model and for the cinematography language itself. This article intends to show how did the dynamics between public, production and exhibition, mostly regarding to sound achievements, enhanced the film development until the consolidation of sound cinema.

Keywords: Sound Cinema - 3D - Exhibition - film language

\section{Lançamentos do Dolby Atmos e do Auro 3d}

A Dolby Laboratories, Inc. anunciou em 23 de abril de 2012 o lançamento da Dolby Atmos, uma nova plataforma de áudio que promete mudar a experiência sonora nas salas de exibição. A promessa é de mais "realismo" por meio de um campo sonoro mais natural e imersivo. Esse lançamento conta com o apoio de empresas renomadas de amplificadores, alto-falantes e softwares, produzindo equipamentos compatíveis e necessários para a implantação do sistema Dolby Atmos nas salas de exibição atuais.

No hotsite do Dolby Atmos (www.dolby.com/atmos) a ênfase é no exibidor e na facilidade de adaptação do sistema atual para o sistema Atmos. A nova plataforma vai propiciar uma experiência que só poderá ser alcançada na sala de cinema, seja ela do tamanho que for, mas sem deixar de ser compativel com as produções que não utilizam essa tecnologia. Nos destaques lê-se: "Os exibidores podem montar suas salas de acordo com o seu ritmo". 
No mesmo compasso a empresa Barco (www.barco.com), ligada à fabricação de projetores e sistemas de exibição (adotados pela rede Cinemark de exibição), lançou a plataforma Auro 3D, que teve sua grande apresentação na estreia, em 20 de janeiro de 2012, do filme "Red Tails", totalmente planejado dentro dessa nova tecnologia e produzido por George Lucas, conhecido por seu trabalho intensivo com o áudio.

O hotsite da plataforma Auro $3 D$ também procura tranquilizar exibidores, atestando que a aquisição do decodificador somada à instalação de caixas adicionais transformarão sua sala em uma Auro $3 D$ por um baixo custo, terminando sua apresentação com a seguinte frase: "O Auto $3 D$ cria um diferencial único permitindo que você mantenha os seus fluxos de receita 3D e se destaque da competição".

Qual a novidade? O modelo atual dominante nas salas de cinema é a distribuição do som em 5.1 canais, ou seja, canais: esquerdo, centro, direito, surround esquerdo, surround direito e baixas frequências. As novas plataformas propõem o modelo 11.1 de distribuição, que mantém os 5.1 canais e adiciona: alto esquerdo, alto centro, alto direito, alto surround esquerdo, alto surround direito e teto, tornando-se tridimensional.

Do hotsite da Barco: "[Auro 3D] transforma o áudio de cinema convencional em uma experiência de som 3D totalmente imersiva, com sons vindos de todos os lados e até mesmo de cima do ouvinte."

Desde o lançamento, essa novidade está sendo adotada por grandes multiplex ao redor do mundo com a função de atrair o público, mas ainda está longe de se tornar o padrão, o que depende da adesão do público. Caso isso ocorra, a produção também precisará se adaptar, para suprir a nova exigência.

A implantação do sistema acarreta investimentos que ficam principalmente a cargo do exibidor, que desde o princípio foi detentor dessa responsabilidade: cabe a ele explorar o encontro da produção com o expectador de forma economicamente viável.

A dinâmica entre a demanda do expectador e o tripé produção/distribuição/ exibição atua desde os primeiros tempos do cinema, sendo responsável pela própria criação da sala de exibição. Esse trabalho procura mostrar como essa relação, no que se refere ao som, impulsionou o desenvolvimento do cinema no Brasil e no mundo até que se consolidasse o filme sonoro. Ele tenta também traçar um paralelo com cenário atual apontando para o potencial de transformações desse cenário que poderá ser trazido pelo som no cinema 3D.

\section{Salas de exibição - formação}

O cinema sonoro, como conhecemos hoje, depende da estrutura física em que se insere. 0 material das poltronas, a espessura da tela, o posicionamento das caixas, o isolamento acústico das paredes, tudo conflui para a experiência sonora ser satisfatória ou não. Essa sofisticação é recente, nos primeiros tempos a exibição era bastante diferente.

As primeiras sessões de cinema (com cobrança de ingresso e em lugar fechado) usavam espaços pré-existentes. A popularmente considerada primeira sessão de cinema, a dos Irmãos Lumière em 1985, se deu em um pequeno café onde se projetaram curtos filmes na parede. Simone Dias, no texto "A trajetória das Salas de Cinema", explica: 
"Modestos comerciantes da época, principalmente donos de mercearias, costumavam ceder o espaço - que ficava ocioso à noite ou nos finais de semana - para as apresentações assinadas pelos cinematógrafos ambulantes. (...) Era um transtorno que valia a pena. Clientes, parentes e vizinhos dos comerciantes não se continham de tanto encantamento. Do improviso de uma projeção simples, que acontecia entre uma estante de mercadorias e outra, a atividade de exibição sinalizava um bom negócio." (DIAS, 1999)

A exibição sinalizava um bom negócio. A pesquisa de Alice Trusz sobre os primeiros tempos do cinema no Brasil procura mostrar como a exibição se configurou na cidade de Porto Alegre-RS, buscando os elementos que formariam a sala de exibição nos moldes que conhecemos (sala especializada com sessões diárias a preço módico, entre outras características). Seu doutorado apresenta a passagem do cinema itinerante, de temporadas, para o cinema sedentário, com salas fixas. O trecho seguinte é de seu livro "Entre Lanternas Mágicas e Cinematógrafos as origens do espetáculo cinematográfico em Porto Alegre 1861-1908", e traz a importância do público no processo:

“... a sedentarização atendeu principalmente a um intuito de reorientar a exploração comercial do cinematógrafo no sentido da racionalização, autonomização e fortalecimento do cinema enquanto prática econômica. Não se tratava de constituir um gênero de espetáculo e uma nova opção de diversão, o que o cinema já era. A formação do público em Porto Alegre foi anterior à sedentarização da exibição, tendo sido o seu maior estímulo, a sua condição. Foi justamente a especialização das práticas e o crescimento do grau de exigência do público do gênero que estimularam a abertura das salas permanentes". (TRUSZ, p322)

Antes da sedentarização, o cinematógrafo era uma atração explorada por mágicos, ilusionistas, mestres do entretenimento, dentistas, fotógrafos, engenheiros, representantes de inventores, enfim, por aqueles que tiveram o interesse desperto, tanto para obter lucro, como pelo fascínio pela nova técnica. O século XIX é um período de modernização do homem, que se encanta pelas novidades tecnológicas e quer se sentir atualizado com as novidades da ciência e das artes.

Sobre o contexto histórico em que o cinema se insere, cito um trecho da introdução de "Tudo que é sólido desmancha no ar - A Aventura da modernidade", de Marshall Berman:

“O turbilhão da vida moderna tem sido alimentado por muitas fontes: grandes descobertas nas ciências físicas, com a mudança da nossa imagem do universo e do lugar que ocupamos nele; a industrialização da produção, que transforma conhecimento científico em tecnologia, cria novos ambientes humanos e destrói os antigos, acelera o próprio ritmo de vida, gera novas formas de poder corporativo e de luta de classes; descomunal explosão demográfica, que penaliza milhões de pessoas arrancadas de seu habitat ancestral, empurrandoas pelos caminhos do mundo em direção a novas vidas; rápido e muitas vezes catastrófico crescimento urbano; sistemas de comunicação de massa, dinâmicos em seu desenvolvimento, que embrulham e amarram, no mesmo pacote, os mais variados indivíduos e sociedades. (...) No século $X X$, os processos sociais que dão vida a esse turbilhão, mantendo-o num perpétuo estado de vir-a-ser, vêm a chamar-se "modernização". (BERMAN, 1986. p16)

O cinema vai se desenvolver no meio urbano, seu público será principalmente de trabalhadores assalariados que buscam uma diversão acessível. O cinematógrafo, além do interesse tecnológico que desperta, possibilita conhecer lugares, pessoas e eventos de maneira mais realista, virando uma febre no mundo. 
Para exemplificar o que isso significou em São Paulo, volto ao texto de Simone Dias:

\begin{abstract}
"Antigos teatros abriam suas portas para o grande público e a partir da criação do primeiro cinema na cidade, o Bijou, em 1907, outros nomes foram compondo a 'sinfonia' da metrópole. Rex, Roxy, Imperial, Plaza, Odeon tornaram-se populares e atraiam verdadeiras multidões". (DIAS, 1999)
\end{abstract}

O preço baixo é muito importante para o sucesso das salas de cinema. Em Porto Alegre, Alice Trusz indica que o ingresso custava o equivalente a 5 passagens de bonde, que não é muito diferente do preço médio atual do cinema no Brasil. Esse é um aspecto que será sempre levado em conta: a viabilidade econômica do empreendimento.

O público de cinema começa a ser disputado pelas salas logo no início de suas atividades, no Brasil esse início se dá entre 1905 e 1908. A qualidade técnica da projeção e o conforto das instalações são destacados como atrativos ou não do público. Com o passar do tempo - principalmente com o advento dos filmes de arte, em 1908 - as salas, muito similares em estrutura, horários e preços, passam a depender da constante renovação do programa para manter o interesse do público, aumentando a preocupação com a produção e a distribuição dos filmes.

Nos primeiros anos do século $X X$, os quadros (pequenas encenações que ocorriam na frente da câmera parada, com a duração média de 40 segundos) e os "naturais" (registros documentais, como fotografias móveis) que compunham o programa das salas de exibição vão se tornando mais complexos.

A partir de 1908, intelectuais e artistas se interessam pelo cinema, e o exibidor deseja absorver o público de maior poder aquisitivo, o que acarreta a primeira grande mudança na linguagem cinematográfica: de esquetes para um conteúdo "elevado", que se inspira em peças de teatro e óperas e depois chegará ao melodrama, e de quadros fixos para o desenvolvimento da montagem, que transforma o cinema numa narrativa linear, de leitura plano a plano.

O conteúdo vira o centro da atenção e os filmes ganham em extensão temporal, caindo no gosto do público e se tornando diferencial na escolha de um exibidor ou de outro.

\title{
O som dentro e fora da tela na formação da exibição sedentária
}

Nos primeiros tempos da exibição, a música era mais utilizada nos intervalos das sessões, na sala de espera. Os indicativos de que a música era apresentada em sincronia com os filmes são poucos, mas existem.

\footnotetext{
"Os problemas musicas preocupavam os cineastas quase desde o inicio, uma vez que logo se reconheceu a importância do acompanhamento musical para o êxito dum filme". (ROSENFELD, 2009, Pag.126)
}

Anatol Rosenfeld-crítico da Revista Íris e estudioso do cinema que atuou nos anos 40 e 50 no Brasil -, em um dos ensaios da coletânea "Cinema: Arte \& Indústria" intitulado "O Filme Sonoro", descreve o uso da música como acompanhamento de filmes no cinema dos primeiros tempos.

Ele aponta que de início o acompanhamento era aleatório, sem relação com o filme, e que com o tempo, principalmente a cargo dos pianistas de cinema, a música passou a acompanhar as ações do filme. Desde então, se enfrentou o problema da sincronia: o maestro, que escolhia as músicas em tempo real, tinha 
dificuldades para manter a trilha musical da orquestra em harmonia com o filme. Enquanto ele escolhia a música pertinente, um pianista fazia improvisações para preencher os "buracos", criando uma trilha musical desequilibrada. Vale lembrar aqui que o quantidade e a qualidade dos músicos de cada sala de cinema era muito variável, e que contar com uma orquestra e um pianista era privilégio de poucos.

Para tentar resolver esse problema, os maestros passaram a ser inteirados dos temas dos filmes com antecedência, o que melhorou a sincronia. Após isso:

“... apareceu, em 1908, um artigo (em Moving Picture World), sobre uma orquestra de um só homem, com instrumentos colocados ao alcance do pianista, para enriquecer o acompanhamento musical. (...). No mesmo ano, apareceu outro artigo no mesmo periódico destacando a distribuição de um rol musical feito para o filme /l Trovatore (1910, França, Pathé), para facilitar ao pianista o trabalho." (ROSENFELD, 2009, Pag. 127)

Se é certo que o cinema não era mudo, podendo contar com o acompanhamento de músicos tocando ao vivo, também é certo que manter um músico, ou vários, contratados era bastante oneroso para o exibidor.

A questão da sincronização de som e imagem por meio de equipamentos elétricos é muito antiga. Fernando Morais da Costa, professor de som na Universidade Federal Fluminense, aponta no texto "Primeiras tentativas de sonorização no Cinema Brasileiro" que Thomas Edison já tinha essa preocupação em 1985, quando apresenta, em Paris, o quinetofone, que une o quinetoscópio com o fonógrafo.

Ainda no texto de Fernando Costa, podemos observar que no Brasil - e no mundo - diversas formas de sincronia (mecânica ou ao vivo) foram utilizadas simultaneamente desde o início das sessões de cinema até o advento do cinema sonoro que se tornou dominante. Os exibidores faziam a combinação por cabeamento de projetores e fonógrafos, explorando os "Cinematógrafos Falantes".

“O mesmo espetáculo provia, portanto, acompanhamento sonoro mecânico, pelo fonógrafo em sincronia com o projetor, e música ao vivo, pela orquestra, ressaltando, ao que tudo indica, que esta não acompanhava os filmes, sendo executada apenas nos intervalos entre eles." (COSTA, 2008)

Costa faz o levantamento da exploração desses "Cinematógrafos Falantes" no Brasil encontrando os primeiros casos já no ano de 1902, com Victor di Maio, que traria a novidade da Europa. Fernando Costa define:

"Era um filme de um rolo, ou seja, o tempo de execução da canção, inserido em uma sessão composta de vários curtas-metragens. O falante seria a atração principal do programa, muitas vezes encerrando a sessão" (COSTA, 2008)

O "Cinematógrafo Falante" volta ao Brasil em 1904, dessa vez em uma grande turnê nacional que atravessa o país de Norte a Sul com o francês Edouard Hervet, que repete o feito entre 1907 e 1908, quando os filmes falantes fazem grande sucesso e Hervet enfrenta concorrência. Entre os concorrentes está William Auler, que ainda no ano de 1908, seria o grande responsável pela próxima sensação brasileira: o "filme cantante" (COSTA, 2008, pag. 34).

É possível perceber que o enfoque é a novidade. Para disputar o público, os exibidores lançavam mão de atrações que fugissem do habitual no cinema, 
atraindo o público de outros espetáculos, como o teatro. Também no Brasil, pouco tempo depois, fazem grande sucesso os "filmes cantantes", que serão na sua maioria produções nacionais.

Até que se resolvessem os problemas de sincronia com o sistema óptico e duplo que temos hoje, as tentativas de sincronizar mecanicamente imagem e som foram muitas, e todas fracassaram por não atingir uma boa sincronia. Não era o caso dos "filmes cantantes".

Os "filmes cantantes" consistem na filmagem da execução de canções que eram sonorizadas ao vivo, por cantores consagrados escondidos atrás da tela. Apesar da absurda ideia de se ter o cantor famoso escondido atrás da imagem cantante, os "filmes cantantes" tinham boa sincronia e foram sucesso absoluto.

Costa apura que a provável primeira produção nacional de um "filme cantante" se deu em 1908 e chama-se "A canção do Aventureiro", de Rubens Guimarães. Porém, o grande produtor do ano de 1908 foi William Auler. William (originalmente Cristóvão Guilherme Auler) era um carioca que passou a juventude nos Estados Unidos. Ao voltar para o Brasil, entra no cinema como fornecedor de cadeiras para as salas, até fundar, em 1907, a sua própria sala de exibição (COSTA, 2008, pag. 35). Auler entra na produção a partir da exibição. Seus "filmes cantantes" provavelmente tinham o intuito de manter a sua sala lucrativa.

Com o sucesso, nos anos seguintes a produção de cantantes aumenta e se diversifica. Esse ciclo de "filmes cantantes" é encerrado em 1911 com o abandono das atividades pelos produtores, porém essas fitas foram muito prestigiadas no Rio de Janeiro e em São Paulo até sua extinção. Uma razão possível para a extinção apontada por Fernando Costa em seu livro "O Som do Cinema Brasileiro", é a entrada do produto estrangeiro combinado com a alta taxação na importação de negativo virgem.

\section{Evolução do sistema de som no cinema}

Um motivo para o sucesso dos filmes cantantes no Brasil é a qualidade da sincronia. Esse é o objetivo perseguido pelos inventores e industriais do cinema no mundo todo: um filme sonoro só se destaca perante o público se tiver boa sincronia.

Carlos Klachquin, consultor da Dolby Laboratories Inc. para a América Latina, apresentou uma palestra na Semana ABC de 2002 que ilustra a evolução do registro de imagem e som sincrônicos do ponto de vista da distribuição e da exibição. Essa palestra foi transcrita e está disponível no site da ABC (www.abcine. org.br/artigos/?id=121\&/o-som-no-cinema).

Segundo Klachquin, a vitrola e o disco prensado surgem em 1910, com ampla distribuição no mercado, é esse equipamento que será a principio empregado nas salas de cinema. Em 1926, Warner Bros e At\&T se unem na criação do Vitaphone, um sistema no qual se acompanhava o filme com um disco de 16 polegadas. Um projetor e um fonógrafo regidos por um mesmo motor elétrico garantiam a sincronia.

Como os discos eram frágeis e de produção dispendiosa, logo se viu a necessidade de se colocar o som na película, barateando os custos de produção e distribuição sem perder a sincronia.

Em 1928 começa a se estabelecer o sistema de som óptico ele

“(...) se torna viável comercialmente. A indústria consegue que ele funcione, que se comercialize, e que seja prático. Não basta ter uma invenção genial, 
ela tem que funcionar de forma prática na realidade da rua, ter um valor que permita a compra, e que as pessoas e a indústria se interessem. É isso que vai definir realmente o sucesso do sistema".

As pequenas salas de exibição que não conseguiram se equipar para acompanhar a novidade do cinema sonoro faliram, deixando para trás o modelo de sala de exibição dos primeiros tempos.

Muitas novas salas foram abertas pelos grandes estúdios, já com o novo sistema e esse crescimento forçou a criação de padrões para a produção e para a exibição, muitos deles válidos até hoje.

O cinema sonoro no Brasil não tardou a chegar. Dados levantados por Fernando Costa em "O Som no Cinema Brasileiro" indicam experiências empíricas inventadas aqui mesmo nos anos de 1927 e 1928, que foram bem recebidas pela crítica por sua carga patriótica latente. Era a chance do cinema nacional aumentar seu espaço no mercado interno, uma vez que o idioma seria uma barreira ao sucesso norteamericano. Em 1929, vemos a chegada dos filmes sonoros norte-americanos em São Paulo numa sala da Paramount... E o sucesso é imenso, ainda que a maioria dos expectadores não entendesse o inglês.

\section{Adaptação da linguagem cinematográfica à tecnologia sonora}

Em todo o mundo, os primeiros filmes sonoros provocaram um engessamento da linguagem cinematográfica que foi visto por muitos críticos como um retrocesso. E era. "Lights of New York" (Bryan Foy, 1928) o segundo filme falado lançado pela Warner Bros., se limita a mostrar diálogos intermináveis em planos parados e próximos. $\mathrm{O}$ que aconteceu para as salas de exibição também ocorreu para a produção: o estúdio passa a viver a ditadura do áudio.

“Com efeito, em 1925-1926 o filme mudo já conquistara tal domínio de seus meios de expressão que os textos explicativos, intercalados, quase se tornaram supérfluos; o filme falado, sobrecarregado de diálogos, não foi, portanto, uma necessidade íntima, mas uma imposição externa da técnica e do fetichismo dos industriais, que não desejavam deixar escapar nenhum aperfeiçoamento técnico por medo da concorrência e na esperança de conquistar um público mais amplo." (ROSENFELD, 2009, pag. 129)

Anatol Rosenfeld explicita nessa passagem um pensamento que foi bastante difundido na época: o cinema sonoro matou a arte cinematográfica. O sucesso de público absoluto dos filmes sonoros foi cruel com a linguagem já estabelecida.

A captação de um filme sonoro era muito diferente da captação muda.

“É oportuno observar que (...) a própria imperfeição dos meios técnicos de gravação prejudicava, no início, a mobilidade e a expressividade da câmera, devido ao enorme acréscimo de aparelhamento sonoro. (...) A gravação simultânea precisava resolver a questão do corte. Usava-se multi-câmeras e músicas compostas com a exata duração da sequência. Qualquer barulho obrigava a refação completa da sequência" (ROSENFELD, 2009, p.129).

Cada cena do filme precisava ser feita de "uma tacada só", com diálogos, ruídos e músicas funcionando em sincronia, e isso tornou a produção mais cara e menos inventiva, porém, a solução foi logo encontrada com o sistema duplo de gravação, onde uma câmera cuidava da imagem e outra cuidava do som óptico, permitindo se cortar imagem e som de forma independente. 
Em 1929, apenas dois anos após o advento do sonoro (1927), é criada a edição de som seguida de mixagem final, que é o modelo atual da produção. Esse novo método devolveu à câmera sua mobilidade e abriu o horizonte do uso criativo do som, que será explorado com inegável valor artístico por grandes cineastas como Fritz Lang, Alfred Hitchcock, Francis Ford Coppola, George Lucas, entre outros.

No Brasil, o cinema sonoro seria logo abraçado pela política populista dos anos 30 , com a promessa de colocar na tela o povo brasileiro em sua própria língua. As primeiras grandes empresas de cinema brasileiras, Atlântida (1941) e Vera Cruz (1949), são do período sonoro.

Movido pelo interesse do público e dos produtores, o cinema entrou de vez em uma nova linguagem e a consolidou. Agora essa linguagem tem em seu encalço as novas tecnologias em três dimensões.

\section{Considerações finais}

Quando a exploração itinerante do Cinematógrafo deixou de ser suficiente para atender a demanda do público de cinema, quem tinha capital para tanto, abriu sua sala fixa para absorver esse público, criando assim uma configuração de espetáculo nova.

Na mesma tônica - a busca pelo público -, o advento do som transformou o mundo do cinema ao mexer na estrutura em todos os níveis do negócio. 0 produtor precisou lidar com a captação de som, o distribuidor precisou resolver o problema das cópias sonoras, e o exibidor teve que adaptar suas salas, mandando para o desemprego todos os envolvidos com a sonorização ao vivo do espetáculo e falindo os pequenos negócios.

“A adaptação para um esquema de filmagem e de exibição sonoras não traria vantagem alguma aos pequenos produtores e exibidores. Pelo contrário, o encarecimento da empreitada sonora sepultaria os pequenos e concentraria o êxito de uma nova fase nas mãos daqueles que pudessem, em termos financeiros, acompanhar as mudanças." (COSTA, 2008, p.86)

O público se interessou imensamente pelo filme falado. A chegada do cinema sonoro possibilitou que os grandes estúdios norte-americanos dominassem o tripé produção/distribuição/exibição, espalhando sua hegemonia e constituindo uma nova configuração de espetáculo, diferente da primeira.

Essa "boa tacada" dos grandes estúdios em instituir um novo padrão de exibição para o qual somente eles possuíam capital para investir, instituiu também uma transformação na linguagem cinematográfica. Esse mesmo efeito já tinha sido visto quando os filmes simples e curtos se tornaram narrativas sofisticadas, por volta de 1908, também em busca de novos públicos para as recém estabelecidas salas fixas de exibição.

Com lançamentos como o Auro 3D e o Dolby Atmos, parece que a nova aposta para atingir o gosto do público que - como foi com o advento do som sincrônico mecânico - não está necessariamente cansado da configuração atual, é o cinema em três dimensões, que após conquistar a imagem com algum sucesso, se embrenha no som.

Se "essa moda pega", os exibidores precisarão se adaptar à nova tecnologia, e novamente haverá uma triagem daqueles que possuem capital contra os que não poderão arcar com a dívida e fecharão suas portas.

Mas há também boas notícias: depois que foi instituído como um caminho sem volta, o cinema sonoro desenvolveu amplamente suas possibilidades criativas. 0 
formato 3D de som e imagem, caso se consolide frente ao público, desenvolverá também sua linguagem. O som 3D está ainda nas suas primeiras experiências comerciais, mas na imagem 3D podemos observar algumas tentativas nesse sentido nas diversas animações infantis lançadas no formato ou em filmes como "Alice in Wonderland" (2010), de Tim Burton e "Hugo" (2012), de Martin Scorcese, onde já começam, com algum sucesso, as pesquisas das possibilidades desse novo mundo.

No Brasil, a empreitada do cinema 3D ainda está muito no começo. É esperar para ver.

\section{Referências bibliográficas}

BERMAN, Marshall. Tudo que é sólido desmancha no ar - A aventura da modernidade. Tradução: MOISÉS, Carlos Felipe e IORIATTI, Ana Maria L.São Paulo: Ed.Schwarcz, 1986.

COSTA, Fernando Morais. O Som no Cinema Brasileiro. Rio de Janeiro: 7letras, 2008.

COSTA, Fernando Morais. (2008). Primeiras Tentativas de sonorização no cinema brasileiro (os cinematógrafos falantes - 1902-1908). Data de Acesso: 18/06/2012. Em:www.mnemocine.art.br/index.php?option $=$ com_content\&view=article\&id= 93:primeiras-tentativas-de-sonorizacao-no-cinema-brasileiro-os-cinematografosfalantes-1902-1908\&catid=42: historia-no-cinema-historia-do-cinema\&ltemid=67

DIAS, Simone. (2008). A trajetória das Salas de Cinema. Data do Acesso: 18/06/2012. Em:www.mnemocine.art.br/index.php?option=com_ content\&view=article\&id=74:a-trajetoria-das-salas-de-cinema\&catid=35: histcine ma\&Itemid $=67$

KLACHQUIN, Carlos. (2002). Seminário ABC - A Imagem Sonora em São Paulo. Palestra ministrada na Cinemateca Brasileira em 09/11/2002. Data do Acesso: 08/06/2012. Em: www.abcine.org.br/artigos/?id=121\&/o-som-no-cinema-

ROSENFELD, Anatol. O Filme Sonoro. In: Arte \& Indústria - Anatol Rosenfeld. Org.: Nanci Fernandes. São Paulo: Perspectiva, 2009.

TRUSZ, Alice Dubina. Entre Lanternas Mágicas e Cinematógrafos - as origens do espetáculo cinematográfico em Porto Alegre - 1861-1908. São Paulo: Editora Terceiro Nome, 2010

Referências da Internet

Making of Dolby Atmos. In: Sound Works Collection. Data do Acesso: 01/06/2012. $\mathrm{Em}$ : soundworkscollection.com/atmos

Hotsite Dolby Atmos. Data do Acesso: 01/06/2012. Em: www.dolby.com/us/en/ professional/technology/cinema/dolby-atmos-exhibitors.html?onlnk=atmosmain-exhib

Hotsite Auro 3D. Data do Acesso: 01/06/2012. Em: www.barco.com/pt/productssolutions/3d-sound/tecnologia-de-som-3d-para-cinema-digital.aspx 